$\mathbb{T}$ periodica polytechnica

Civil Engineering

$57 / 1(2013) 7782$

doi: 10.3311/PPci.2143

http://periodicapolytechnica.org/ci

Creative Commons Attribution (1)

RESEARCH ARTICLE

\section{New procedures to estimate soil erodibility properties from a hole erosion test record}

\author{
Mohamed Amine Boukhemacha / Ioan Bica / Khoudir Mezouar
}

Received 2010-02-18, revised 2012-06-07, accepted 2012-12-21

\begin{abstract}
The estimation of representative values of the properties quantifying soil erodibility (critical shear stress and coefficient of soil erosion) is of great difficulty. The difficulty lies in the complexity of the phenomenon in question in addition to the uncertainty of the used experimentation (hole erosion test). In this paper, the procedure used to estimate these properties is presented, and two new procedures are proposed. The proposed procedures are more accurate for the quantification as well as to detect the initiation of the internal erosion. It is found that the erodibility properties depend on the hydraulic charge and that for one soil sample, it is possible to find more than one pair of solutions (critical shear stress, coefficient of soil erosion) which explains the non-observation of significant relationship between these two properties and other soil properties.
\end{abstract}

\section{Keywords}

critical shear stress $\cdot$ coefficient of soil erosion $\cdot$ hydraulic shear stress · hole erosion test $\cdot$ internal erosion

\section{Mohamed Amine Boukhemacha}

Groundwater Engineering Research Center, Technical University of Civil Engineering of Bucharest, Bd. Lacul Tei, nr. 124, 020396, Sec. 2, Bucharest, Romania

e-mail: boukhemacha-amine@ hotmail.com

\section{Ioan Bica}

Groundwater Engineering Research Center, Technical University of Civil Engineering of Bucharest, Bd. Lacul Tei, nr. 124, 020396, Sec. 2, Bucharest, Romania

\section{Khoudir Mezouar}

Technical University of Civil Engineering of Bucharest, Bd. Lacul Tei, nr. 124, 020396, Sec. 2, Bucharest, Romania

\section{Introduction}

The erodibility of a soil can be quantified in terms of the rate of erosion when a given hydraulic shear stress is applied to the soil, and the ease of initiating erosion in the soil. This can be expressed as [3]:

$$
\dot{\varepsilon}=C_{e}\left(\tau_{t}-\tau_{c}\right)
$$

where $\dot{\varepsilon}\left[\mathrm{kg} / \mathrm{s} / \mathrm{m}^{2}\right]$ is the rate of erosion per unit surface area of the hole at time $t, C_{e}[\mathrm{~s} / \mathrm{m}]$ is a constant named the coefficient of soil erosion, $\tau_{t}[\mathrm{~Pa}]$ is the hydraulic shear stress along the hole at time $t$ and $\tau_{c}[\mathrm{~Pa}]$ is the minimum hydraulic shear stress for initiation of erosion, also known as the critical shear stress.

The previous equation is applicable when $\left(\tau_{t}>\tau_{c}\right)$ only, otherwise the erosion rate is equal to zero. The hydraulic shear stress for a horizontal cylindrical hole can be calculated using [4]:

$$
\tau_{t}=\frac{\gamma_{w} D_{t} H}{4 L}
$$

where $\gamma_{w}$ is the specific weight of water, $D_{t}[\mathrm{~m}]$ is the hole diameter at time $t, L[\mathrm{~m}]$ is the hole length and $H[\mathrm{~m}]$ is the head loss along the hole due to friction.

The estimation of representative values of the coefficient of soil erosion $\left(C_{e}\right)$ and the critical shear stress $\left(\tau_{c}\right)$ is of great difficulty, and makes use of mixed techniques: experimental and mathematical modeling. For the experimental part, it is possible to perform a constant head [5] Hole Erosion Test (HET) for example. This test provides a record that gives the change in flow rate through a leak of known initial diameter, as a result of a given hydraulic head. This variation is due to the increase of the hole diameter which in turn is caused by the internal erosion of internal surface of the hole. The mathematical modeling part is used to estimate the change in the diameter of the leak over time, since it is not possible to measure this change during the test (in the experimental part). Some mathematical models for internal erosion were developed by Wan \& Fell [5], Bonelli et al. [1] and Boukhemacha [2]. 


\subsection{Wan and Fell (2004)}

The model can be used to estimate the erosion-induced variation of the hole diameter in time from a HET record (which gives the time variation of the flow rate through the hole), and it is given [5] for laminar and turbulent flow (Eq. (3)).

$$
D_{t}=\left\{\begin{array}{l}
\left(\frac{16 \cdot Q_{t} \cdot f_{L t}}{\pi \cdot \rho_{w} \cdot g \cdot S_{t}}\right)^{\frac{1}{3}}, \text { laminar flow } \\
\left(\frac{64 \cdot Q_{t}^{2} \cdot f_{T_{t}}}{\pi^{2} \cdot \rho_{w} \cdot g \cdot S_{t}}\right)^{\frac{1}{5}}, \text { turbulent flow }
\end{array}\right.
$$

where $Q_{t}\left[\mathrm{~m}^{3} / \mathrm{s}\right]$ is the flow rate at time $t, S_{t}$ is the hydraulic gradient at time $t, f_{L t}\left[\mathrm{~kg} / \mathrm{m}^{2} / \mathrm{s}\right]$ and $f_{T t}\left[\mathrm{~kg} / \mathrm{m}^{2} / \mathrm{s}\right]$ is a friction factor for laminar and turbulent flow condition, respectively. The friction factors are determined by interpolating between two values that can be estimated, including the beginning and end of the test (the moments when the diameter of the hole is known) by [5] :

$$
\left\{\begin{array}{c}
f_{L t}=\frac{\rho_{w} g \pi S_{t}}{16} \frac{D_{t}^{3}}{Q_{t}} \\
f_{T t}=\frac{\rho_{w} g \pi^{2} S_{t}}{64} \frac{D_{t}^{5}}{Q_{t}^{2}}
\end{array}\right.
$$

\subsection{Bonelli et al. (2006)}

The model is developed [1] from the equations for diphasic flow with diffusion, and the equations of jump with erosion. It can estimate the hole diameter variation in time as follows:

$$
\frac{D_{t}}{D_{0}}=1+\left(1-\frac{4 L \tau_{c}}{D_{0} \gamma_{w} H}\right)\left[\exp \left(\frac{C_{e} \gamma_{w} H}{2 L \rho_{d}} t\right)-1\right]
$$

where $D_{0}[\mathrm{~m}]$ is the initial diameter of the hole and $\rho_{d}\left[\mathrm{~kg} / \mathrm{m}^{3}\right]$ is the dry density of the soil.

\subsection{Boukhemacha (2009)}

A piping erosion mathematical model is developed [2] from the equations of soil erodibility, pipe flow and mass conservation. This model consists in two equations: the first one gives the variation of the hole radius in time (Eq. (6)), while the second one gives the flow rate variation as a function of the hole diameter (Eq. (7)):

$$
\begin{gathered}
R_{t}=R_{0}+\left(\frac{4 L \rho_{d}-C_{e} R_{0} \gamma_{w}}{2 C_{e} H \gamma_{w}}\right)\left[\left(1+\frac{2 C_{e} H \gamma_{w}}{4 L \rho_{d}-C_{e} R_{0} \gamma_{w}}\right)^{t}-1\right] \\
\left(\frac{2 C_{e} H \gamma_{w} R_{0}}{4 L \rho_{d}-C_{e} R_{0} \gamma_{w}}+\frac{4 C_{e} L \tau_{c}}{C_{e} H \gamma_{w}-4 L \rho_{d}}\right) \\
Q_{t}=0.4824 \frac{D_{t}^{2}}{\sqrt{L}} \sqrt{D_{t} g H\left[1.2676-0.5 \ln \left(\frac{D_{t}^{3} g H \rho_{w}^{2}}{L \mu^{2}}\right)\right]^{2}}
\end{gathered}
$$

where $R_{t}[\mathrm{~m}]$ is the hole radius at time $t, R_{0}[\mathrm{~m}]$ is the hole initial radius, $\rho_{w}\left[\mathrm{~kg} / \mathrm{m}^{3}\right]$ is the water density and $\mu$ is the dynamic coefficient of viscosity of water (taken to be equal to $10^{-3} \mathrm{~kg} / \mathrm{m} . \mathrm{s}$ at $20^{\circ} \mathrm{C}$ ).

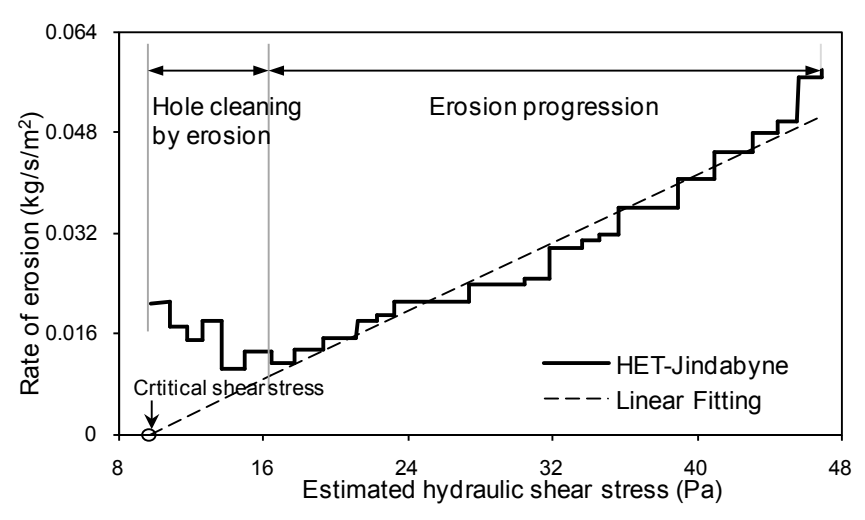

Fig. 1. Th curve $\dot{\varepsilon}=\dot{\varepsilon}\left(\tau_{t}\right)$ for a HET record using Wan and Fell [5] procedure

\section{Data and Methods}

\subsection{Procedures for soil erodibility properties estimation}

The most common procedure to estimate the critical shear stress and the coefficient of soil erosion is to use the linear relationship between the erosion rate and the hydraulic shear stress, as it is presented in equation (1). To do so, it is necessary to estimate the rate of erosion for different values of the hydraulic shear stress. The rate of erosion can be estimated [5] using equation (8):

$$
\dot{\varepsilon}=\frac{\rho_{d}}{2} \frac{d D_{t}}{d t} \cong \frac{\rho_{d}}{2} \frac{\Delta D_{t}}{\Delta t}
$$

In the construction of the linear relationship between $\tau_{c}$ and $C_{e}$ and in addition to their model given in equations (3) and (4), Wan and Fell [5] used equations (2) and (8). They considered that for the transition between two successive diameters (two successive values of the hydraulic shear stress) the value of the erosion rate is constant. Figure 1 represents typical results that can be obtained with this procedure.

\subsubsection{Proposed extrapolation, $\mathrm{PP}(\mathrm{EXT})$}

It is possible to use the model of Boukhemacha [2] to estimate $\tau_{c}$ and $C_{e}$ by extrapolation. The authors propose to use a procedure similar to that described previously (procedure of Wan and Fell [5]), only that this time equation (7) will be used instead of equations (3) and (4). The diameter of the hole at a given time will be estimated by solving equation (7) using NewtonRaphson method by considering that the initial value of the diameter for every step is equal to the value of the previous step solution. Also, the calculation of the hydraulic shear stress will not be conducted for each value of the diameter, but for a fictitious value that represents the transition between the two values of the diameter, and which will be taken equal to the average diameter. Thus, for each value of the rate of erosion, there will be only one value for the hydraulic stress. Figure 2 represents typical results that can be obtained with this procedure. 


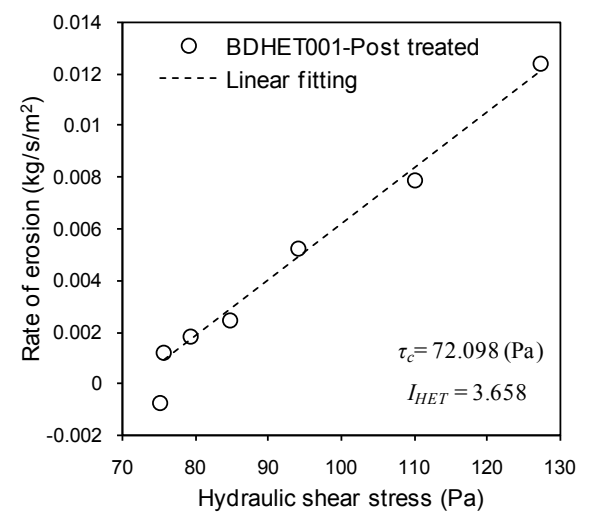

Fig. 2. Th curve $\dot{\varepsilon}=\dot{\varepsilon}\left(\tau_{t}\right)$ for a HET record using the PP(EXT)

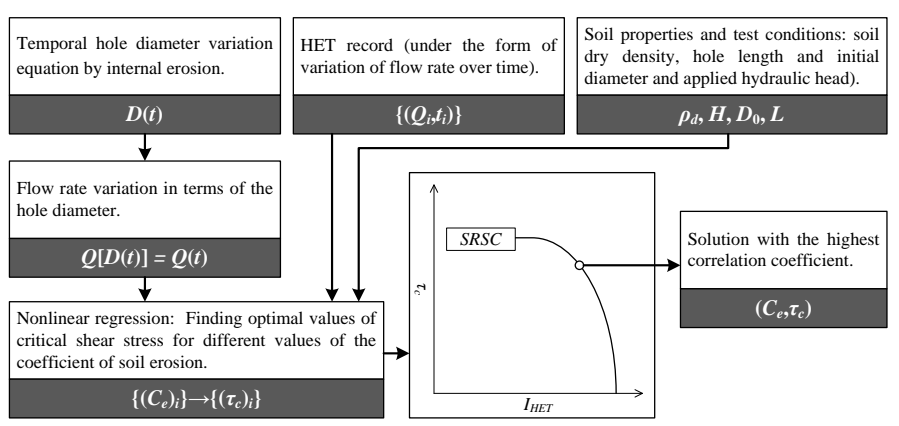

Fig. 3. Descriptive schema for PP(REG) and the Set of Regression Solutions Curve determination

\subsubsection{Proposed regression, $\mathrm{PP}(\mathrm{REG})$}

One can also estimate the values of $C_{e}$ and $\tau_{c}$ by nonlinear regression. The authors propose to use the equation obtained by substituting the diameter from equation (7) by its temporal variation expression given in equation (6). This operation will give a set of solutions (values of $C_{e}$ and $\tau_{c}$ with different values of the correlation coefficient), the retained solution is the one with the highest correlation coefficient. This procedure is described in Figure 3 The curve representing the set of solutions obtained during this procedure will be called Set of Regression Solutions Curve (SRSC). This curve is useful for the results discussion.

\subsection{Data used in this study}

This study was carried out using 36 HET records from [6]. These records are for 36 different soil samples from 9 different origins. The hole erosion tests were conducted on samples compacted at different water contents and under different hydraulic charges.

Figure 4 shows the 36 HET records obtained from [6], whose test conditions are given in Table 1 . These records give the flow rate variation in time measured during the test as a result of the application of a constant hydraulic head. The initial diameter of the horizontal hole drilled through each sample is $6 \mathrm{~mm}$, and its length is about $116 \mathrm{~mm}$.
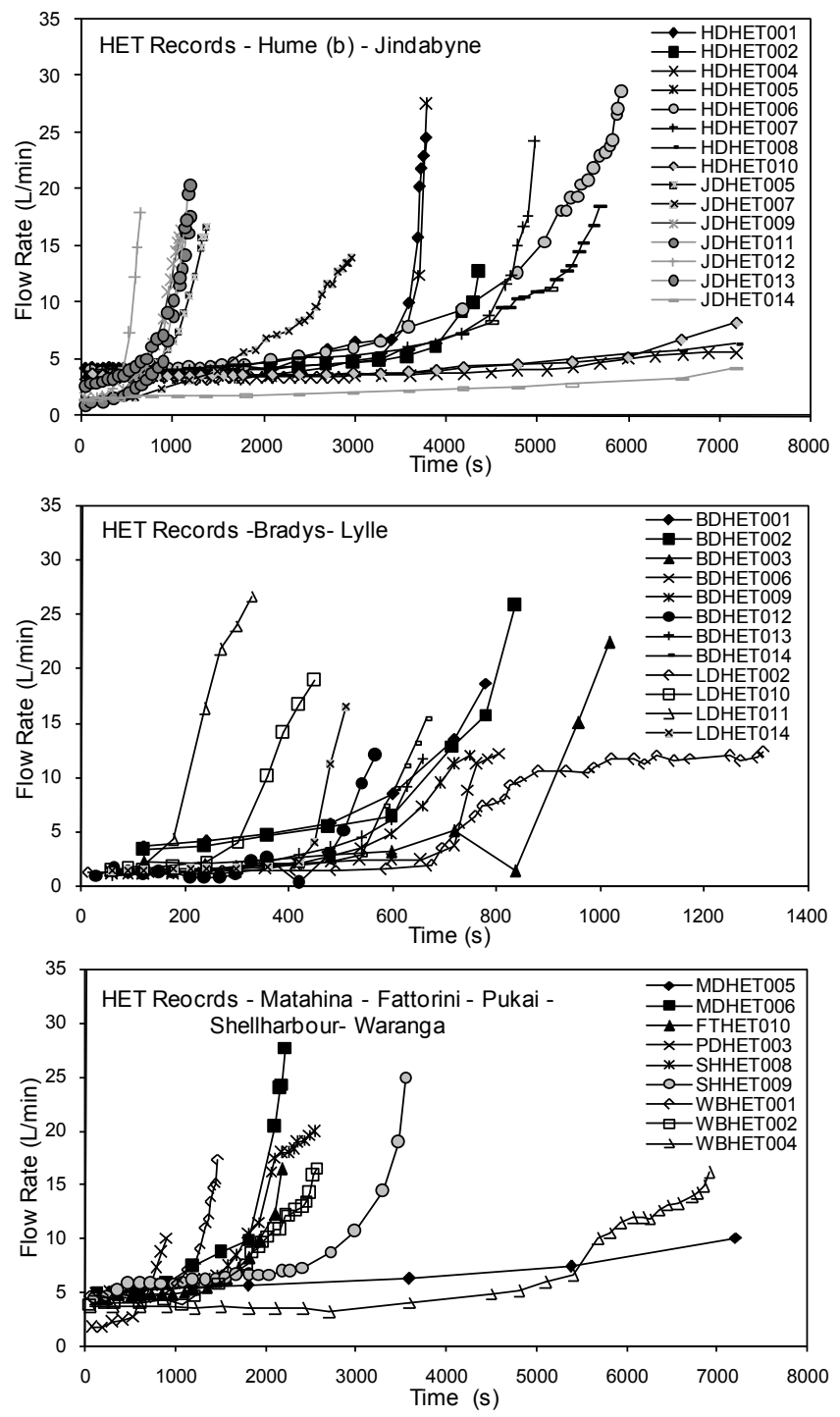

Fig. 4. HET records for the 36 soil samples used in the study (Data from [6])

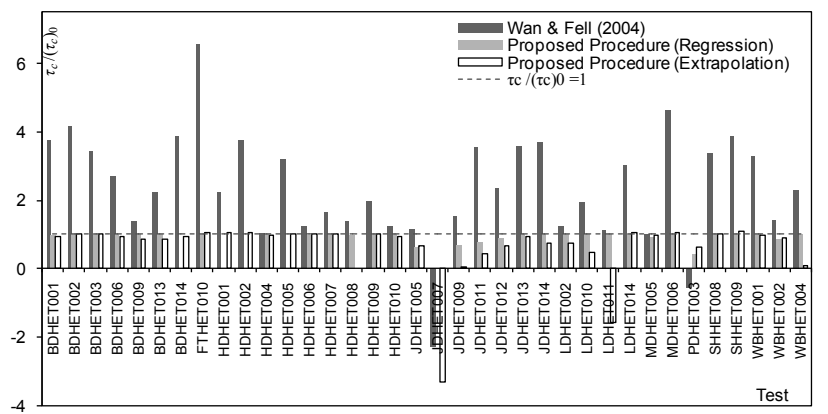

Fig. 5. Summary of the obtained values of the ratio $\tau_{c} /\left(\tau_{t}\right)_{0}$ 
Tab. 1. Summary of the results of the different procedures for the studied HET records

\begin{tabular}{|c|c|c|c|c|c|c|c|c|c|}
\hline \multirow{3}{*}{ Origin } & \multirow{3}{*}{ Test } & \multirow{3}{*}{$H(\mathbf{m})$} & \multirow{3}{*}{$\rho_{d}\left(\mathbf{k g} / \mathbf{m}^{3}\right)$} & \multicolumn{6}{|c|}{ Procedures } \\
\hline & & & & \multicolumn{2}{|c|}{ Wan \& Fell $|5|$} & \multicolumn{2}{|c|}{ PP(REG) } & \multicolumn{2}{|c|}{ PP(EXT) } \\
\hline & & & & $I_{H E T}$ & $\tau_{c}(\mathbf{P a})$ & $I_{H E T}$ & $\tau_{c}(\mathbf{P a})$ & $I_{H E T}$ & $\tau_{c}(\mathbf{P a})$ \\
\hline \multirow{7}{*}{ Bradys } & BDHET001 & 0.60 & 1240.8 & 3.72 & 284.04 & 3.72 & 73.27 & 3.66 & 72.10 \\
\hline & BDHET002 & 0.40 & 1234.2 & 3.50 & 211.85 & 3.50 & 49.23 & 3.42 & 51.69 \\
\hline & BDHET003 & 0.20 & 1234.2 & 3.13 & 87.14 & 3.13 & 25.17 & 3.04 & 25.57 \\
\hline & BDHET006 & 0.05 & 1214.4 & 2.38 & 17.17 & 2.38 & 6.31 & 2.51 & 5.92 \\
\hline & BDHET009 & 0.05 & 1280.4 & 2.47 & 8.61 & 2.47 & 6.18 & 2.70 & 5.45 \\
\hline & BDHET013 & 0.05 & 1273.8 & 2.13 & 14.04 & 2.13 & 6.34 & 2.70 & 5.45 \\
\hline & BDHET014 & 0.05 & 1247.4 & 2.02 & 24.39 & ** & ** & 2.46 & 5.87 \\
\hline Fattorini & FTHET010 & 0.70 & 1611.5 & 4.06 & 582.99 & 4.06 & 87.04 & 3.72 & 91.64 \\
\hline \multirow{9}{*}{ Hume (b) } & HDHET001 & 0.70 & 1541.6 & 3.29 & 197.02 & ** & $\star \star$ & 3.64 & 91.55 \\
\hline & HDHET002 & 0.60 & 1541.6 & 3.63 & 284.72 & ** & $* *$ & 3.64 & 79.63 \\
\hline & HDHET004 & 0.50 & 1549.8 & 4.37 & 64.05 & 4.37 & 63.22 & 4.60 & 61.98 \\
\hline & HDHET005 & 0.50 & 1504.2 & 3.61 & 202.35 & ** & ** & 3.32 & 64.72 \\
\hline & HDHET006 & 0.60 & 1590.8 & 4.50 & 93.84 & 4.50 & 71.91 & 4.38 & 75.59 \\
\hline & HDHET007 & 0.60 & 1492.4 & 3.92 & 125.53 & 3.92 & 76.09 & 3.89 & 77.93 \\
\hline & HDHET008 & 0.60 & 1599.0 & 4.82 & 103.61 & 4.82 & 73.20 & $*$ & * \\
\hline & HDHET009 & 0.60 & 1541.6 & 4.27 & 150.14 & 4.27 & 75.72 & 4.28 & 76.97 \\
\hline & HDHET010 & 0.60 & 1549.8 & 4.45 & 93.05 & 4.45 & 75.73 & 4.46 & 71.86 \\
\hline \multirow{7}{*}{ Jindabyne } & JDHET005 & 0.05 & 1688.7 & 2.99 & 7.28 & 2.99 & 3.87 & 2.98 & 4.19 \\
\hline & JDHET007 & 0.05 & 1715.0 & 3.65 & -14.43 & 3.56 & 0.00 & 3.98 & -21.00 \\
\hline & JDHET009 & 0.05 & 1671.3 & 2.87 & 9.68 & 2.67 & 4.20 & 3.06 & 0.39 \\
\hline & JDHET011 & 0.05 & 1610.0 & 2.53 & 22.40 & 2.67 & 4.90 & 2.86 & 2.84 \\
\hline & JDHET012 & 0.05 & 1583.8 & 2.51 & 14.91 & 2.51 & 5.45 & 2.58 & 4.19 \\
\hline & JDHET013 & 0.40 & 1662.5 & 3.25 & 182.03 & 3.40 & 50.34 & 3.56 & 46.98 \\
\hline & JDHET014 & 0.10 & 1706.3 & 3.42 & 46.70 & 3.70 & 12.50 & 4.15 & 9.35 \\
\hline \multirow{4}{*}{ Lylle } & LDHET002 & 0.05 & 1881.6 & 1.12 & 7.72 & 2.30 & 6.25 & 2.18 & 4.58 \\
\hline & LDHET010 & 0.05 & 1881.6 & 1.86 & 12.06 & 1.92 & 6.27 & 2.52 & 2.88 \\
\hline & LDHET011 & 0.10 & 1862.0 & 2.01 & 14.21 & 2.01 & 12.59 & 3.15 & -20.00 \\
\hline & LDHET014 & 0.05 & 1793.4 & 1.30 & 19.09 & 2.00 & 6.31 & 1.96 & 6.67 \\
\hline \multirow{2}{*}{ Mattahina } & MDHET005 & 1.00 & 1755.7 & 5.10 & 124.52 & 5.10 & 116.22 & 4.84 & 124.88 \\
\hline & MDHET006 & 1.00 & 1737.6 & 3.77 & 585.89 & 4.00 & 126.35 & 3.97 & 133.50 \\
\hline Pukai & PDHET003 & 0.10 & 2012.5 & 3.27 & -7.11 & 3.27 & 5.22 & 3.08 & 7.81 \\
\hline \multirow{2}{*}{ Shellharbour } & SHHET008 & 0.80 & 1223.0 & 4.16 & 340.91 & 4.16 & 100.35 & 4.14 & 101.64 \\
\hline & SHHET009 & 0.80 & 1185.6 & 4.22 & 391.46 & 4.22 & 101.27 & 3.98 & 110.79 \\
\hline \multirow{3}{*}{ Waranga } & WBHET001 & 0.80 & 1611.6 & 3.99 & 332.18 & 3.79 & 101.05 & 3.75 & 98.50 \\
\hline & WBHET002 & 0.60 & 1586.5 & 4.40 & 108.71 & 4.40 & 64.07 & 4.18 & 68.38 \\
\hline & WBHET004 & 0.50 & 1594.9 & 4.25 & 143.89 & 4.25 & 63.12 & 4.44 & 5.99 \\
\hline
\end{tabular}

$\left.{ }^{*}\right)$ The value of $C_{e}$ is negative. $\left({ }^{* *}\right)$ No good solution.
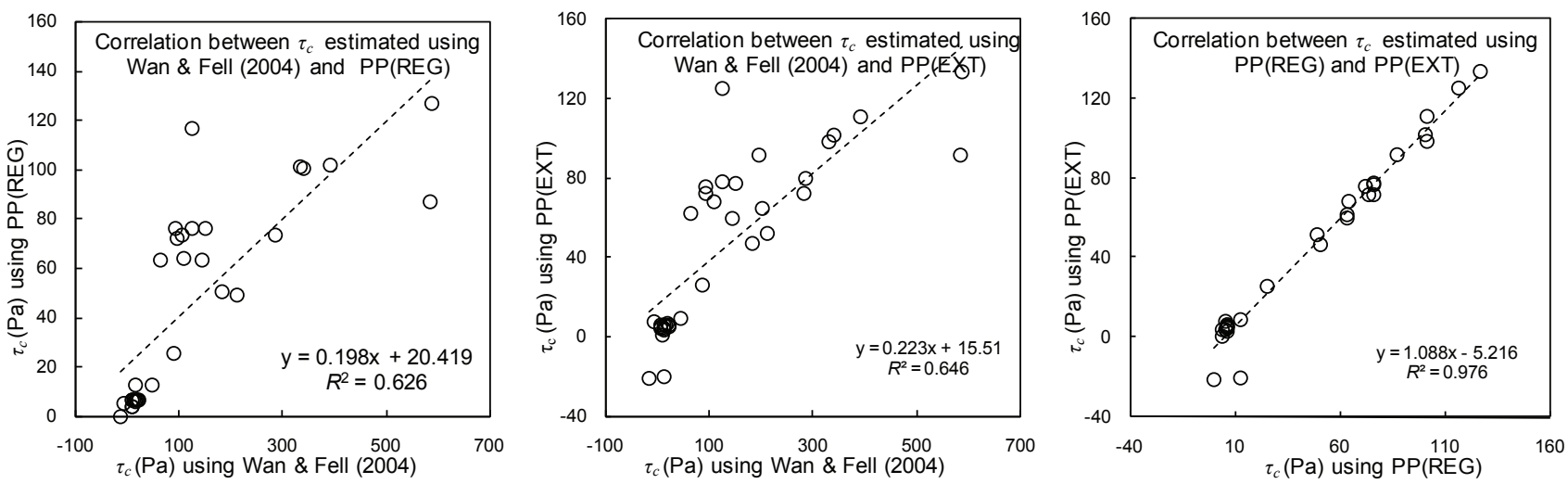

Fig. 6. Correlation coefficients between the values of critical shear stress estimated by the three procedures taken two by two 

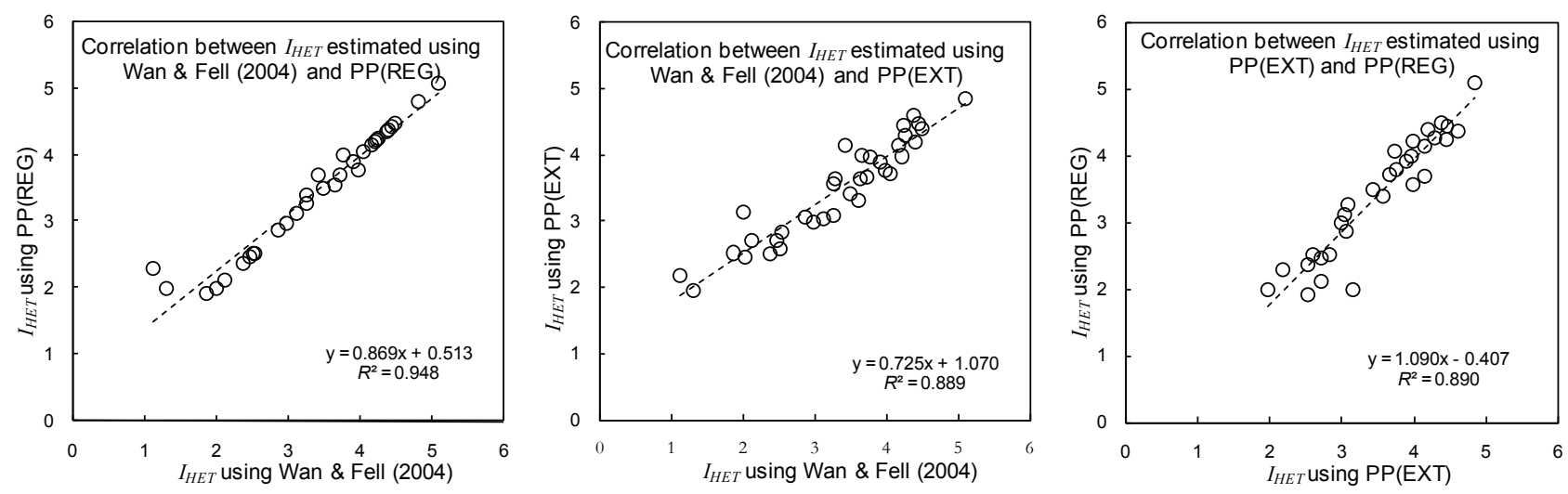

Fig. 7. Correlation coefficients between the values of erosion rate index estimated by the three procedures taken two by two

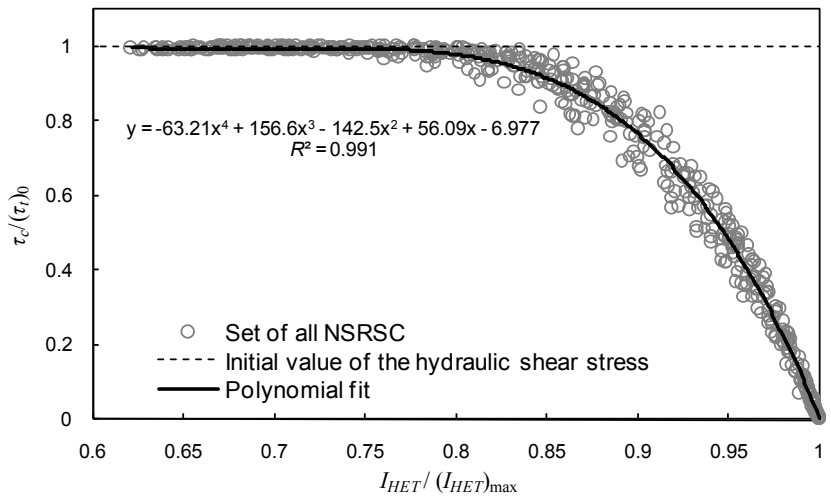

Fig. 8. The set of all the NSRSC for the 34 HET records

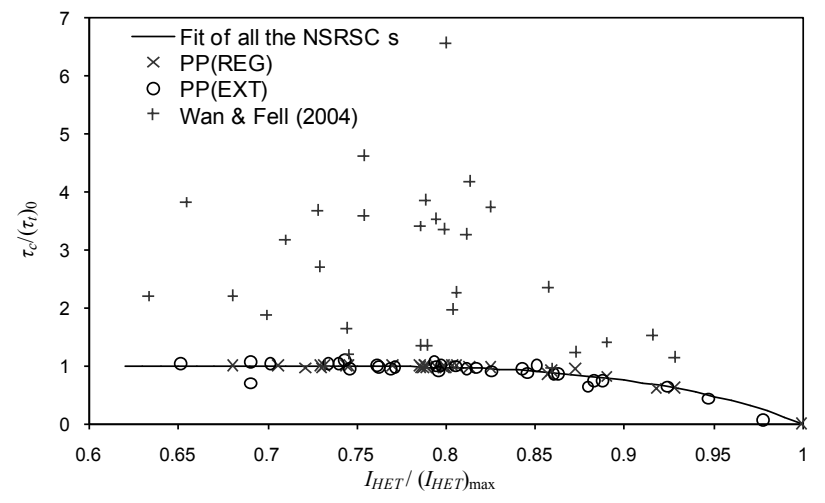

Fig. 9. Representation of the solutions of the different procedures on the fitted NSRSC

\section{Results and discussion}

The results of the estimation of representative values of $C_{e}$ and $\tau_{c}$ for the available experimental data using the previously described procedures; the procedure of Wan and Fell [5] and the two proposed procedures, are summarized in Table 1 . Since the values of $C_{e}$ are very small, it is more practical to present its values in terms of the erosion rate index noted $I_{H E T}$ and defined as:

$$
I_{H E T}=-\log _{10}\left(C_{e}\right)
$$

To compare the obtained results of $C_{e}$ and $\tau_{c}$ by the different procedures, each property will be considered separately, and then the two properties will be taken together.

\subsection{Critical shear stress}

By comparing the values of the critical shear stress to the initial value of hydraulic shear stress (noted $\left(\tau_{t}\right)_{0}$ and calculated using the initial diameter of the hole $D_{0}$ ) one can easily notice that:

- In most cases summarized in Table 1 the procedure of Wan and Fell [5] gives a ratio of $\tau_{c} /\left(\tau_{t}\right)_{0}$ greater than unity, which means that the erosion should not take place, whereas the HET records clearly indicate that erosion has taken place. Therefore this procedure has failed to detect the initiation of internal erosion (see Figure 5 .

- On the other hand, in most cases in Table 1, the values of $\tau_{c}$ estimated by the proposed procedures, PP(EXT) and PP(REG), are less than $\left(\tau_{t}\right)_{0}$. Therefore these two procedures are able to predict the initiation of internal erosion (see Figure 5).

Figure 5 summarizes the values of the ratio $\tau_{c} /\left(\tau_{t}\right)_{0}$ for the different records using different procedures.

The observed correlation coefficient $\left(R^{2}\right)$ between the values of $\tau_{c}$ estimated by the procedure of Wan and Fell [5] and each of the proposed procedures is low (about 63\%), and it is high between the values estimated by the two proposed procedures (approximately 93\%) as shown in Figure 6 


\subsection{Erosion rate index}

The correlation coefficient between the values of $I_{H E T}$ estimated by Wan and Fell [5] and PP(REG) is high (about $95 \%$ ), and it is significant between the values estimated by the two other combinations of procedures (approximately 89\%), as shown in Figure 7

\subsection{Critical shear stress and erosion index rate}

To compare the results obtained by the different procedures in terms of $\tau_{c}$ and $I_{H E T}$ simultaneously, the previously defined SRSC is used. This curve can be normalized by means of the following change of variables:

$$
\left\{\begin{array}{l}
\tilde{I}_{H E T}=\frac{I_{H E T}}{\left(I_{H E T}\right)_{\max }} \\
\tilde{\tau}_{c}=\frac{\tau_{c}}{\left(\tau_{t}\right)_{0}}
\end{array}\right.
$$

Where, $\left(I_{H E T}\right)_{\max }$ is the regression solution corresponding to $\tau_{c}=0$ and $\left(\tau_{t}\right)_{0}$ is the hydraulic shear stress at the beginning of the test estimated using $D_{0}$.

The set of all the Normalized SRSC (NSRSC) for the studied records are shown in Figure 8 in which is represented a limit for the values of $\tilde{\tau}_{c}$ corresponding to the line $\left(\tilde{\tau}_{c}=1\right)$. The data from the set of all the NSRSC accept with a high coefficient of correlation $\left(R^{2}=0.991\right)$ the polynomial fitting given in equation 11 (see Figure 8):

$$
\begin{aligned}
\tilde{\tau}_{c}= & -63.212 \tilde{I}_{H E T}^{4}+156.64 \tilde{I}_{H E T}^{3}-142.54 \tilde{I}_{H E T}^{2} \\
& +56.096 \tilde{I}_{H E T}-6.997
\end{aligned}
$$

Thus, the values of the pair $\left(I_{H E T}, \tau_{c}\right)$, obtained by the different procedures are represented on the fitting curve of the set of all the NSRSC as shown in Figure 9 The optimal points of $\mathrm{PP}(\mathrm{REG})$ are by design on NSRSC. What is interesting is that in most cases, even the points of PP(EXT) are on or very close to the NSRSC, when most points from Wan and Fell [5] procedure are far from this curve. This means that even if the two proposed procedures give different solutions, the obtained pairs of $\left(I_{H E T}, \tau_{c}\right)$ are able to quantify and to detect the initiation of the erosion with an acceptable precision, which is not the case using Wan and Fell [5] procedure.

\section{Conclusions}

The estimation of representative values of the parameters quantifying soil erodibility is of great difficulty. The difficulty lies in the complexity of the phenomenon in question in addition to the uncertainty of the experimentation used for this estimation.

Using piping erosion mathematical modeling, two new procedures for the quantification of the coefficient of soil erosion and the critical shear stress are proposed. This quantification consists on the interpretation of hole erosion test records.

The two proposed procedures give a better estimation of the critical shear stress and the coefficient of soil erosion. They both can detect the initiation of erosion. The authors recommend the use of the PP(REG).

It was found that for a given experimental record, it is possible to find more than one pair of solutions (critical shear stress, coefficient of soil erosion). This will make it difficult to observe any possible relationship between these variables and other soil properties. In addition, the values of these variables showed an interaction with the applied hydraulic charge.

\section{Acknowledgment}

The authors would like to give special thanks to Prof. Robin Fell from the University of New South Wales and to Dr. Chi Fai Wan for their valuable experimental data.

\section{References}

1 Bonelli S, Brivois O, Borghi R, Benhamed N, On the modelling of piping erosion, Comptes Rendus Mecanique, 334, (2006), 555-559, DOI 10.1016/j.crme.2006.07.003.

2 Boukhemacha M, A Hole Erosion Test Model A Step on Internal Erosion Modeling, Scientific Bulletin Series: Mathematical Modelling in Civil Engineering, 5(3), (2009), 17-24

3 Duboys M, Le Rhône et les rivières à lit affouillable, Annales des Ponts et Chaussées, 5(18), (1879), 141-195.

4 Fell R, Wan C, Methods for estimating the probability of failure of embankment dams by internal erosion and piping in the foundation and from embankment to foundation, The University of New South Wales, Sydney, 2005. UNICIV Report No. R-436, $151 \mathrm{p}$

5 Wan C, Fell R, Laboratory tests on the rate of piping erosion of soils in embankment dams, Geotechnical Testing Journal, 27(3), (2004), 295-303, DOI 10.1520/GTJ11903.

6 Wan C, Fell R, Investigation of internal erosion and piping of soils in embankment dams by the slot erosion test and the hole erosion test, The University of New South Wales, Sydney, 2002. UNICIV Report No. R-412, p. 400. 